\title{
Photodissociation Mechanism Study of 1, 3-Dibromopropane using Theoretical Calculations*
}

\author{
Received : 7/12/2017
}

Accepted : 18/1/2018

\author{
Roaa A-Hussien and Abbas A-Ali Drea \\ University of Babylon, College of Science, Department of Chemistry \\ Email: aadreab22@yahoo.com
}

\begin{abstract}
$\underline{\text { Abstract: }}$
A simulation study has been conducted by using Quantum calculation methods like DFT, Ab-initio and semiempirical methods to estimate the photolysis mechanism for 1,3-dibromopropane in the gas phase and its effect on the ozone layer.

Energetic properties have been calculated like total energy and thermodynamic functions $\left(\mathrm{G}, \mathrm{S}, \mathrm{H}_{\mathrm{f}}\right)$ for all chemical species that's participate in the suggested reaction mechanism. Geometry optimized and single point calculation has been done to understand the configuration interaction singly excited state for three different conformations of 1,3-dibromopropane which is found that the $\mathrm{C}_{2}$ isomer is the most stable with total energy being equal to $-26652.031 \mathrm{kCal} \mathrm{mol}^{-1}$. Molecular orbital and their energy gap has been calculated using Ab initio//6-311G* and Beak $88 \mathrm{LYP} / / 3-21 \mathrm{G}(\mathrm{d})$ level.
\end{abstract}

The cleavage occurs at a wavelength equal to $442.571 \mathrm{~nm}$ and yields the 3-bromopropyl and bromine radical with activation energy equal to $98.624 \mathrm{kCal} \mathrm{mol}^{-1}$ calculated by using MNDO/d method. The 3bromopropyl radical undergoing secondary dissociation through second $\mathrm{C}-\mathrm{Br}$ bond to give the cyclopropane molecule as a final product with an energy barrier equal to $68.83 \mathrm{kCal} \mathrm{mol}^{-1}$.

Key words:1,3-dibromopropane,Ozone Depletion, Photolysis mechanism, transition state, Calculation methods.

\section{Introduction:}

The depletion of the ozone layer, which was discovered 40 years ago that's resulted from compounds released to the atmosphere in the course of various industrial or technological human activities such as chlorofluorocarbons (CFC) and halons, has been of great environmental interest and has attracted numerous experimental and theoretical studies [1].The concentration of ozone in the atmosphere is decreasing and large holes are being formed near the poles.
These changes are directly attributed to anthropogenic halogens compounds with chlorine, bromine and iodine have the most potential for atmospheric ozone depletion.[2] Hydrochlorofluorocarbons (HCFC) are chemical compounds that have been identified as a replacement to CFC and halon compounds which have a shorter atmospheric lifetime and less ozone depletion potential due to oxidation by hydroxyl $(\mathrm{OH})$ radical. These compounds undergo photolysis releasing 
the halogens that participate in the ozone depletion cycles. Bromine radical which contributes in catalytic ozone destruction is $40-50$ times more effective than $\mathrm{Cl}$ at depleting ozone [3-5].

Brominated hydrocarbons can have a significant impact on the degradation of stratospheric ozone due to bromine radical reactivity in ozone depletion cycle compared with chlorine radical [6] . Brominated hydrocarbons are very shortlived compounds that's suggested as replacements for chlorofluorocarbons in according to the Montreal Protocol on substances that deplete the ozone layer. When these compounds transported and photolyzed in the stratosphere, can produce $\mathrm{Br}$ atoms that participate in ozone destruction cycle an important example of these compounds is bromopropane. Bromopropane has been used as the active component of industrial cleaning solvents where under UV-radiation undergoing photoreaction consists of excitation of nonbonding $p$ electron of bromine directly to the lowest energy available antibonding molecular orbital followed by a quick dissociation, which involving $n \rightarrow$ $\sigma^{*}$ electronic excitation localized on the $\mathrm{C}-\mathrm{Br}$ bond [7-10].

1,3-Dibromopropane is a colorless to light brown liquid which is a very important

\section{Computational Details:}

All quantum mechanics calculations are done using the Hyperchem 8.02 program package. Geometries were calculated using the HF and DFT with Beak 88 exchange potential and LYP correlation potential with implemented of 3-21G(d) basis set. Single point energies have been calculated to estimate the total energy and electrostatic properties for all ground-state compound to form $\mathrm{C}_{3}$-bridged compounds such as cyclopropane by using sodium as a catalyst that's proposed by Freund in 1881. 1,3-dibromopropane present in three conformations with respect to the rotation along the $\mathrm{C}-\mathrm{C}$ bonds, these are the antianti, anti-gauche and the gauche-gauche conformation and there is a conformational equilibrium between these isomers [11-12].

The present study tends to investigate the photolysis net equation for 1,3dibromopropane under the influence of UV-radiation and geometry optimized determination of the species result in photolysis reactions and its interaction with ozone in the stratospheric layer by using quantum computational methods such as semiempirical, $A b$ initio/HF and DFT/ Beak 88 LYP also, vibration analysis has been predicted to estimate the zero point energy and stationary points on the potential energy surface. Transition state searching has been done by using synchronous transit method with a quadratic option to evaluate the activation energy of the reactions and the most probable pathway [13-15].

species. Potential energy surface of bond stability had been performed at PM3/ Configuration Interaction/Singly Excited (4*4) level of theory to the bond length, bond angle of 1,3-dibromopropane and molecular orbital energies (HOMO and LUMO) with energy gap have been computed by Austin Model 1method [16 18]. 


\section{RESULTS AND DISCUSSION:}

\section{Optimizing structure of 1,3-Dibromopropane conformations:}

1,3-Dibromopropane compound has been optimized under different quantum computational methods in three different conformations with respect to the rotation along the $\mathrm{C}-\mathrm{C}$ bonds as given in Fig.1.The energetic properties of these three conformations have been calculated using the PM3 method as represented in Table1. The anti-anti conformation takes $\mathrm{C}_{2 \mathrm{~V}}$ symmetry, gauche-gauche with $\mathrm{C}_{2}$ symmetry and the last conformation gauche-anti with $\mathrm{C}_{1}$ symmetry.

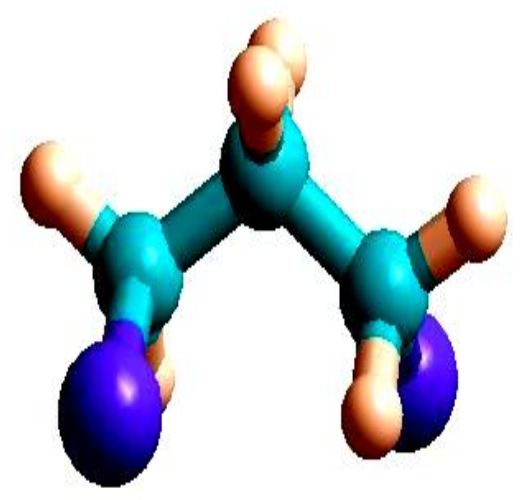

$C_{2}$ symmetry

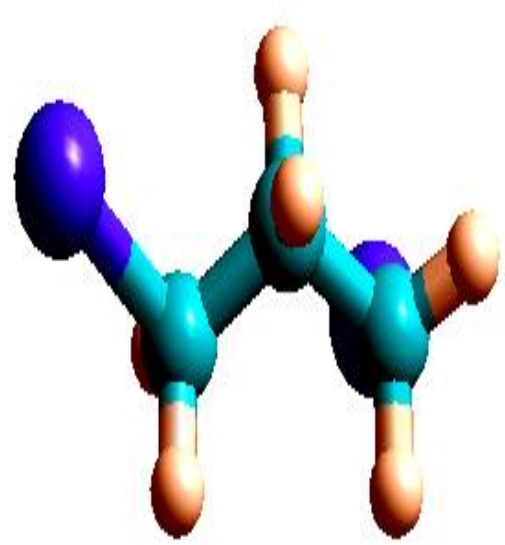

$C_{1}$ symmetry

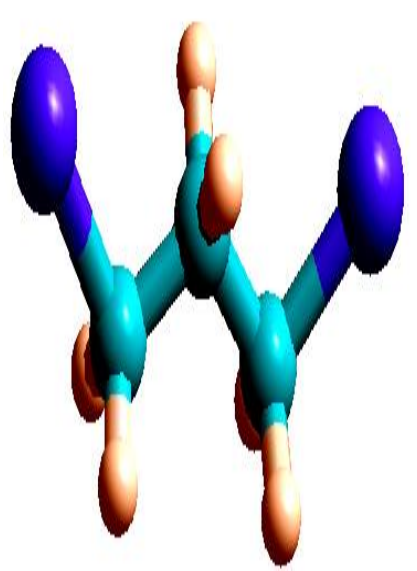

$C_{2 V}$ symmetry $\mathrm{H}$

Figure 1: Geometry optimized of DBP conformations calculated at DFT/3- $\mathrm{Br}$ 21G(d) level of theory.

Table 1: Energetic properties of DBP conformations calculated at PM3 method, energy values in $\mathrm{kCal} \mathrm{mol}^{-1}$ unit.

\begin{tabular}{|c|c|c|c|}
\hline \multirow{2}{*}{ Type of calculations } & \multicolumn{3}{|c|}{ symmetry } \\
\cline { 2 - 4 } & gauche-gauche & gauche-anti & anti-anti \\
\cline { 2 - 4 } & $\boldsymbol{C}_{\boldsymbol{2}}$ & $\boldsymbol{C}_{\boldsymbol{I}}$ & $\boldsymbol{C}_{\boldsymbol{2}}$ \\
\hline Total energy & -26652.03096 & -26651.6711 & -26651.4958 \\
\hline Binding energy & -888.1 & -887.7374 & -887.562 \\
\hline Heat of formation & -9.4993 & -9.147 & -8.9794 \\
\hline Dipole moment D & 1.626 & 1.803 & 1.823 \\
\hline ZPE & 52.8288 & 52.611 & 52.531 \\
\hline HOMO eV & -11.0655 & -11.09445 & -11.0928 \\
\hline LUMO eV & -0.35 & -0.4367 & -0.5665 \\
\hline $\mathrm{E}_{\mathrm{g}} \mathrm{eV}$ & 10.7155 & 10.6578 & 10.526 \\
\hline
\end{tabular}


They found the relative stabilities of 1,3dibromopropane have been reported as $67 \% \mathrm{GG}, 30 \% \mathrm{AG}$ and $3 \% \mathrm{AA}$, where $\mathrm{C}_{2}$ symmetry conformation is the more stable isomer than other isomers of DBP, which proved with the lowest value of the total energy compared with recent studies [1921].The geometry optimization of gauche- gauche conformation also, has been computed by using other semiempirical methods such as AM1, MNDO/d and $A b$ initio, DFT methods as shown in Table 2. The energy gap calculation gives high value with $A b$ initio method compared with semiempirical, which equal to 14.691 $\mathrm{eV}$.

Table 2: DBP energy values computed with different methods in $\mathrm{kCal} \mathrm{mol}^{-1}$ unit.

\begin{tabular}{|c|c|c|c|c|}
\hline \multirow{2}{*}{ Type of calculation } & \multicolumn{2}{|c|}{ Semiempirical } & Ab initio & DFT \\
\cline { 2 - 5 } & AM1 & MNDO/d & $\mathbf{6 - 3 1 1 G}$ & $\mathbf{3 - 2 1 G ( d )}$ \\
\hline Total energy & -27078.02 & -22298.394 & -3301874.961 & -3288853.863 \\
\hline Binding energy & -893.359 & -872.395 & - & - \\
\hline Heat of formation & -15.733 & 6.366 & - & - \\
\hline Dipole moment D & 1.621 & 1.862 & 2.531 & 2.338 \\
\hline ZPE & 53.1 & 56.1 & 57.563 & 36.206 \\
\hline HOMO eV & -10.727 & -10.453 & -11.198 & -6.417 \\
\hline LUMO eV & 0.622 & 0.443 & 3.493 & -1.346 \\
\hline $\mathrm{E}_{\mathrm{g}} \mathrm{eV}$ & 11.349 & 10.896 & 14.691 & 7.763 \\
\hline
\end{tabular}

\section{Investigation of 1,3-Dibromopropane bonds reactivity :}

Chemical reactivity of 1,3Dibromopropane is achieved by comparing the bond stability of real molecular structure. Table 3 represented the bond parameters, bond length and bond angles were computed by a PM3 method. The values of $\mathrm{C}-\mathrm{Br}, \mathrm{C}_{1}-\mathrm{C}_{2}$ bond length also, $\mathrm{C}_{1}-\mathrm{C}_{2}-\mathrm{C}_{3}$ angle reached the values computed by the DFT method in recent studies[12].

Table 3: Bonds parameters of DBP conformations computed at PM3 method.

\begin{tabular}{|c|c|c|c|c|c|c|}
\hline \multirow{2}{*}{ Bonds } & \multicolumn{3}{|c|}{ Bond length $(\AA)$} & \multicolumn{3}{c|}{ Bond angle(Degree) } \\
\cline { 2 - 7 } & $\begin{array}{c}\boldsymbol{C}_{\boldsymbol{2}} \\
\text { symmetry }\end{array}$ & $\begin{array}{c}\boldsymbol{C}_{\boldsymbol{I}} \\
\text { symmetry }\end{array}$ & $\begin{array}{c}\boldsymbol{C}_{\boldsymbol{2}} \\
\text { symmetry }\end{array}$ & $\begin{array}{c}\boldsymbol{C}_{\boldsymbol{2}} \\
\text { symmetry }\end{array}$ & $\begin{array}{c}\boldsymbol{C}_{\boldsymbol{I}} \\
\text { symmetry }\end{array}$ & $\begin{array}{c}\boldsymbol{C}_{\boldsymbol{2} \boldsymbol{V}} \\
\text { symmetry }\end{array}$ \\
\hline $\mathrm{C}_{2}-\mathrm{C}_{3}$ & 1.499 & 1.497 & 1.5 & - & - & - \\
\hline $\mathrm{C}_{1}-\mathrm{Br}_{4}$ & 1.959 & 1.952 & 1.952 & - & - & - \\
\hline $\mathrm{C}_{1}-\mathrm{H}_{5}$ & 1.1 & 1.102 & 1.101 & - & - & - \\
\hline $\mathrm{C}_{1}-\mathrm{C}_{2}$ & 1.499 & 1.5 & 1.5 & - & - & - \\
\hline $\mathrm{C}_{2}-\mathrm{H}_{8}$ & 1.1097 & 1.1092 & 1.109 & - & - & - \\
\hline $\mathrm{C}_{3}-\mathrm{H}_{9}$ & 1.102 & 1.1 & 1.1 & - & - & - \\
\hline $\mathrm{C}_{1}-\mathrm{Br}_{4}-\mathrm{H}_{5}$ & - & - & - & 107.348 & 108.17 & 107.837 \\
\hline $\mathrm{C}_{2}-\mathrm{H}_{7}-\mathrm{C}_{1}$ & - & - & - & 109.544 & 109.606 & 109.913 \\
\hline $\mathrm{C}_{1}-\mathrm{C}_{2}-\mathrm{C}_{3}$ & - & - & - & 112.554 & 112.01 & 111.552 \\
\hline $\mathrm{C}_{2}-\mathrm{C}_{3}-\mathrm{H}_{7}$ & - & - & - & 109.513 & 109.873 & 109.953 \\
\hline
\end{tabular}

The physical properties of 1,3dibromopropane have been calculated with semiempirical AM1 method as represented in Fig 2. The electrostatic potential at three 
dimension mapped isosurface showed with red and green color, where the red color centered on the bromine atom which

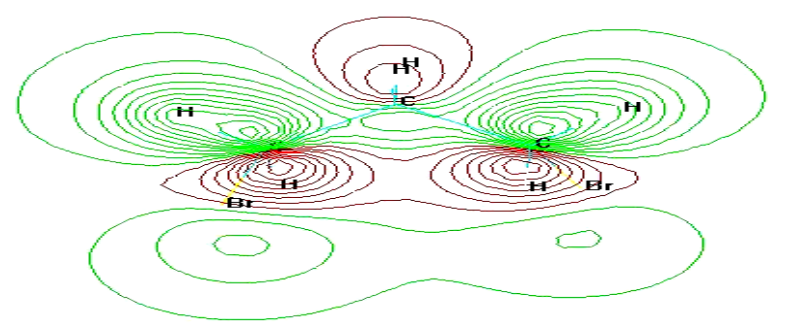

$\mathrm{HOMO}$ at $2 \mathrm{D}$ contours

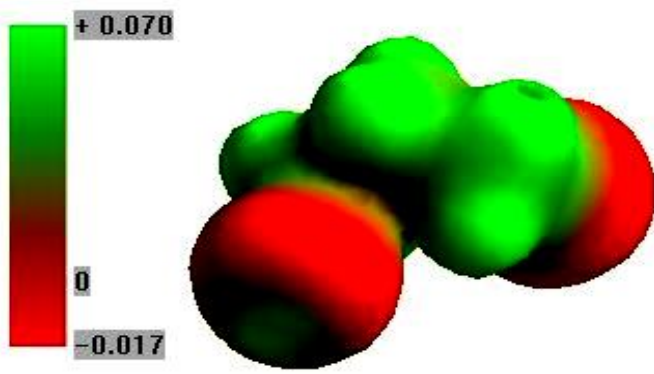

Electrostatic potential at 3D mapped isosurface represented the negative charge density while green color is a positive charge density [22].

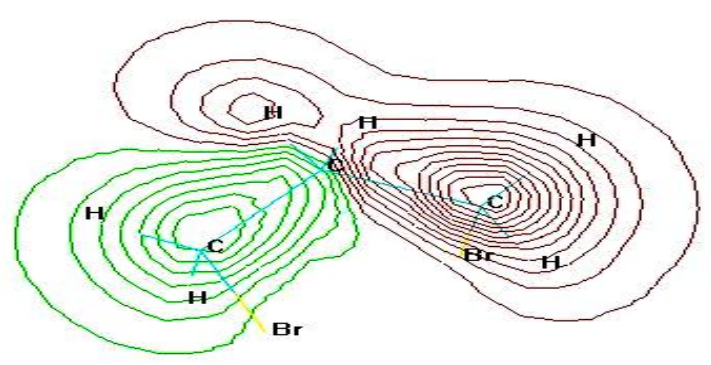

LUMO at 2D contours

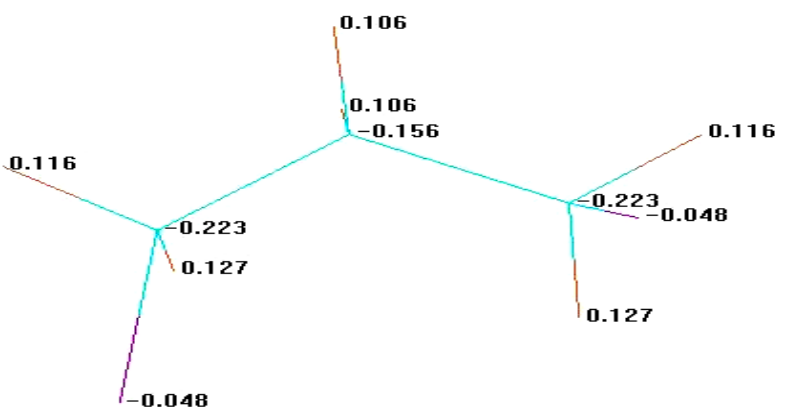

Sticks view with atomic charges

\section{Figure 2: Physical properties of DBP computed at semiempirical AM1 method.}

The potential energy stability has been used to predict the bond length, bond angle reactivity of 1,3-dibromopropane molecule and finding the most probable bond in photolysis reaction. Energetic values of main bonds in 1,3-DBP molecule have been calculated by using PM3/ $\mathrm{CI}(4 * 4)$ method as given in Table 4 and Fig. 3 [17].

Table 4:Potential energy stability search of bonds length computed at $\mathrm{PM3} / \mathrm{CI}\left(4^{*} 4\right)$ in kCal mol ${ }^{-1}$ unit.

\begin{tabular}{|c|c|c|c|c|c|}
\hline $\begin{array}{c}\text { Type of } \\
\text { bonds }\end{array}$ & $\begin{array}{c}\text { Equilibrium } \\
\text { energy }\end{array}$ & $\begin{array}{c}\text { Equilibrium } \\
\text { length } \AA\end{array}$ & $\begin{array}{c}\text { Breaking } \\
\text { energy }\end{array}$ & $\begin{array}{c}\text { Dissociation } \\
\text { energy }\end{array}$ & $\begin{array}{c}\text { Wavelength } \\
\text { nm }\end{array}$ \\
\hline $\mathrm{C}_{1}-\mathrm{Br}_{4}$ & -888.1 & 1.959 & -823.712 & 64.39 & 442.571 \\
$\mathrm{C}_{1}-\mathrm{H}_{6}$ & -888.097 & 1.102 & -776.527 & 111.57 & 256.52 \\
$\mathrm{C}_{1}-\mathrm{C}_{2}$ & -888.097 & 1.499 & -785.527 & 102.57 & 279.01 \\
$\mathrm{C}_{2}-\mathrm{C}_{3}$ & -888.097 & 1.499 & -785.516 & 102.582 & 278.977 \\
$\mathrm{C}_{2}-\mathrm{H}_{8}$ & -888.097 & 1.11 & -788.709 & 99.389 & 287.939 \\
$\mathrm{C}_{3}-\mathrm{H}_{10}$ & -888.096 & 1.102 & -779.585 & 108.51 & 263.736 \\
$\mathrm{C}_{1}-\mathrm{H}_{5}$ & -888.0973 & 1.1 & -779.531 & 108.566 & 263.6 \\
\hline
\end{tabular}



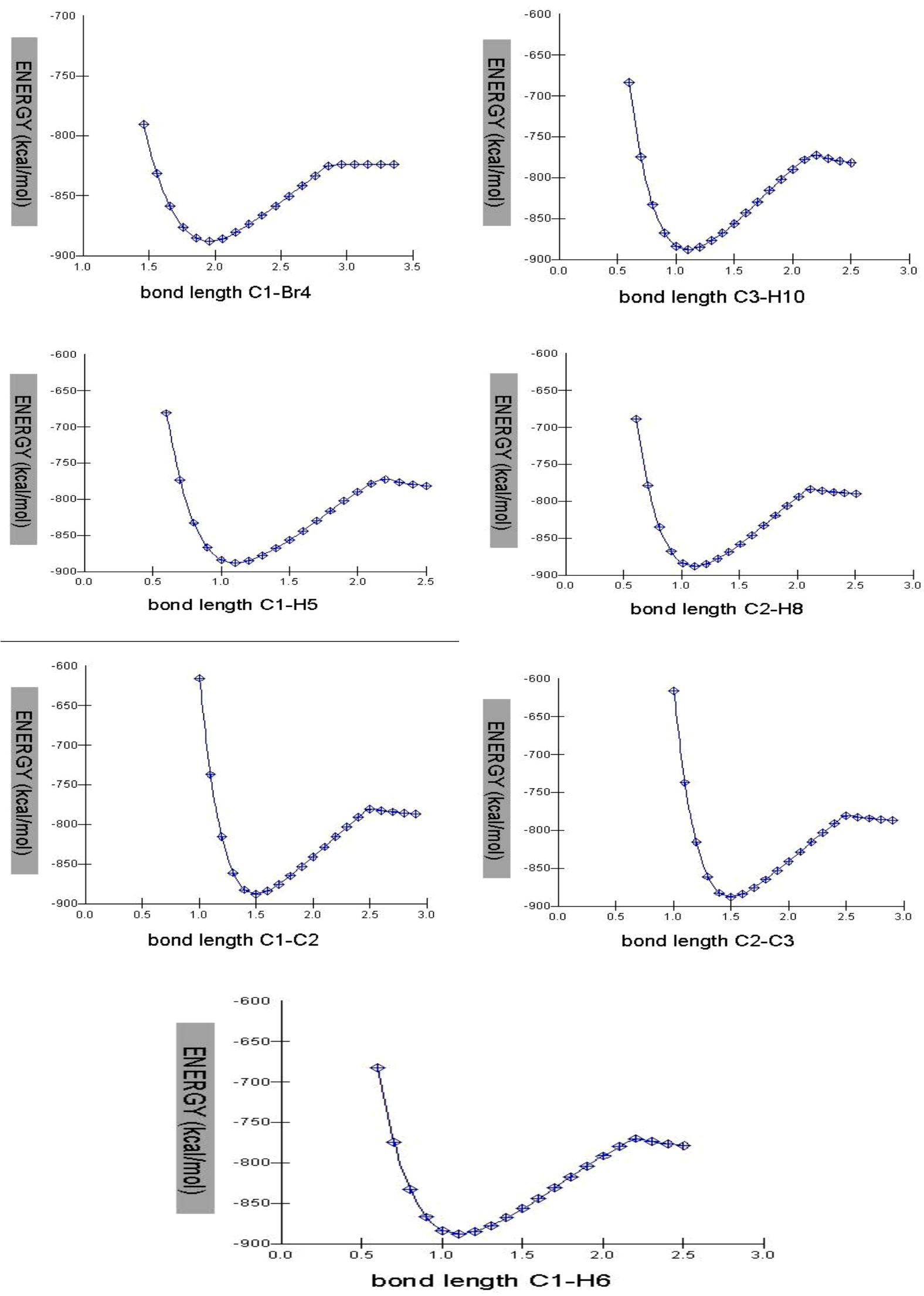

Figure 3: Potential energy surface of 1,3-DBP computed at PM3/CI $(4 * 4)$ method. 
These values predict that $\mathrm{C}-\mathrm{Br}$ bond is less stable than $\mathrm{C}-\mathrm{H}$ and $\mathrm{C}-\mathrm{C}$ bonds toward photolysis due to its bond length equal to $1.959 \AA$, and it is required less energy to be a breakdown, also it is required less value of dissociation energy which equal to

\section{Photolysis pathways of 1,3-DBP:}

The first photodissociation path is the breakdown of $\mathrm{C}-\mathrm{Br}$ bond with a dissociation energy and wavelength equal to $64.39 \mathrm{kCal} \mathrm{mol}^{-1}, \quad 442.571 \mathrm{~nm}$ respectively. The 3-bromopropane radical which is the main molecule in photodissociation pathways is the product of this path. The potential energy surface has been computed for this molecule to
$64.39 \mathrm{kCal} \mathrm{mol}^{-1}$, with a wavelength value $442.571 \mathrm{~nm}$ where the breakdown of $\mathrm{C}-\mathrm{Br}$ bond occurs in the visible region. The dissociation energy of $\mathrm{C}-\mathrm{C}$ and $\mathrm{C}-\mathrm{H}$ agreed with recent experimental and theoretical studies [7], [23].

predict the most reactive bond as shows in Table 5 and Fig.4.The potential energy surface calculation of 3-bromopropane radical shows that three types of bonds will undergo photodissociation $\mathrm{C}_{2}-\mathrm{H}_{7}, \mathrm{C}_{3}$ $\mathrm{Br}$ and $\mathrm{C}_{2}-\mathrm{C}_{3}$ to give us a different fragment that contribute to ozone depletion.

Table 5 : Potential energy surface of bond length for 3-bromopropane radical computed at $\mathrm{PM} 3 / \mathrm{CI}(4 * 4)$ method in $\mathrm{kCal} \mathrm{mol}^{-1}$ unit.

\begin{tabular}{ccccc}
\hline Type of bonds & $\begin{array}{c}\text { Equilibrium } \\
\text { energy }\end{array}$ & $\begin{array}{c}\text { Equilibrium } \\
\text { length } \AA\end{array}$ & Breaking energy & Dissociation energy \\
$\mathrm{C}-\mathrm{H}$ & -832.723 & 1.08 & -713.482 & 119.24 \\
$\mathrm{C}_{2}-\mathrm{H}_{7}$ & -832.723 & 1.11 & -754.413 & 78.31 \\
$\mathrm{C}_{3}-\mathrm{Br}$ & -832.723 & 1.958 & -751.858 & 80.865 \\
$\mathrm{C}_{3}-\mathrm{H}_{9}$ & -832.7 & 1.1 & -726.168 & 106.555 \\
$\mathrm{C}_{1}-\mathrm{C}_{2}$ & -832.72 & 1.463 & -727.399 & 105.323 \\
$\mathrm{C}_{2}-\mathrm{C}_{3}$ & -821.841 & 1.363 & -723.895 & 97.946 \\
\hline
\end{tabular}

The second photodissociation path is the dissociation of ${ }^{-} \mathrm{C}_{2}-\mathrm{H}_{7}$ to form 3bromopropene compound and released hydrogen radical. The geometry optimized of 3-bromopropene have been calculated with $A b$ initio method as represented in Fig.5 .The third photodissociation pathway is the breakdown of $\mathrm{C}_{2}-\mathrm{C}_{3}$ to give us ethene and $\mathrm{CH}_{2} \mathrm{Br}$ radical. Geometry optimized of the ethene molecule has been computed by using density functional theory as given in Fig.6. The dipole moment calculation gives zero value due to symmetry in electronic density distribution among the ethene molecule. 

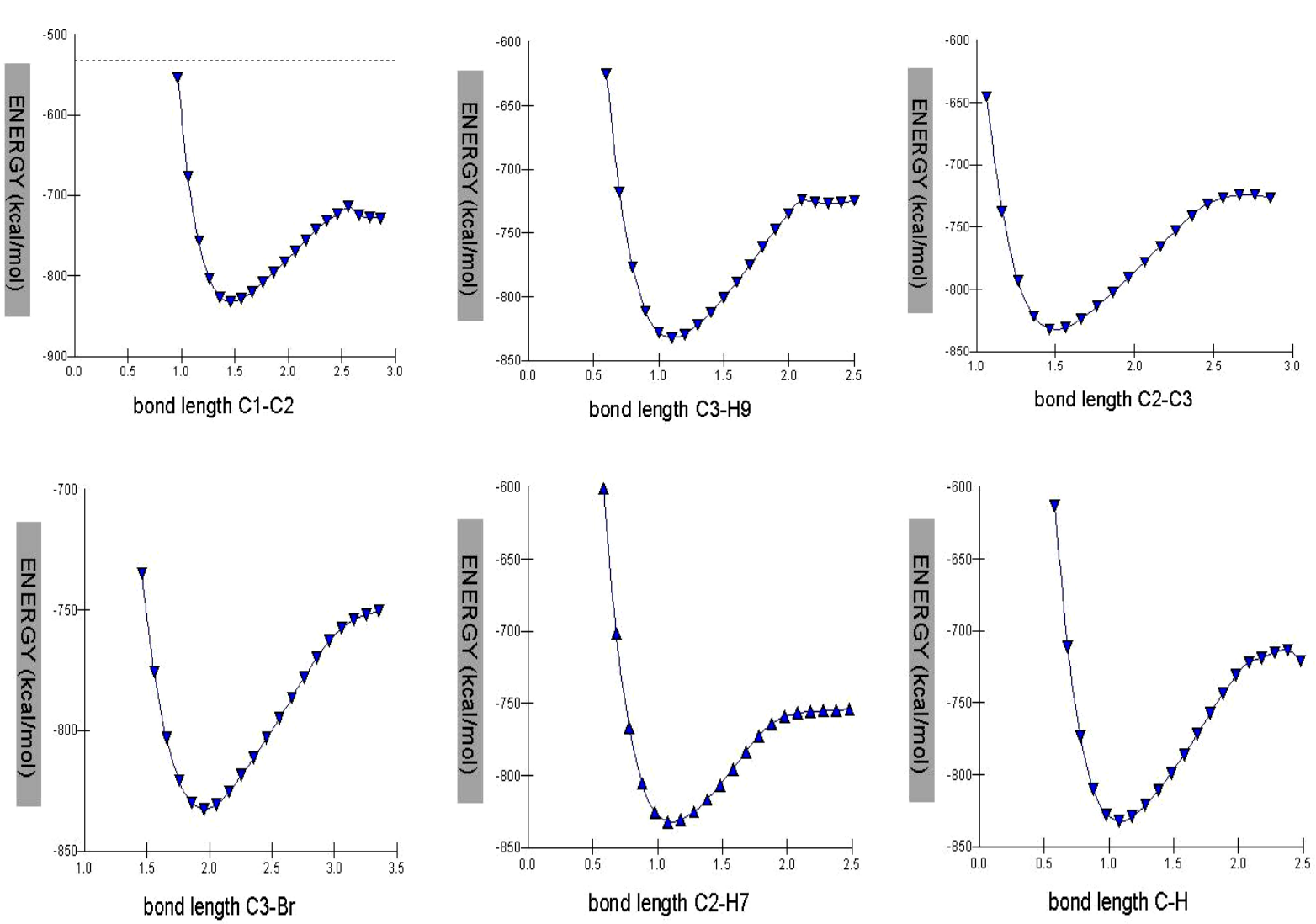

Figure 4 : Potential energy surface of 3-bromopropane radical calculated at PM3/CI $(4 * 4)$ method.

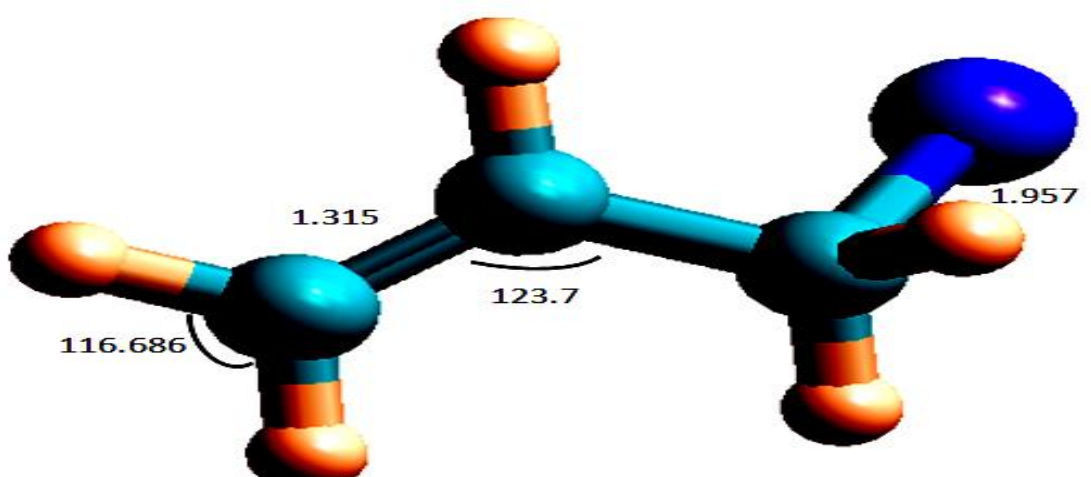

Figure 5: Geometry optimized of 3-bromopropene calculated at $A b$ initio/321G(d) method.

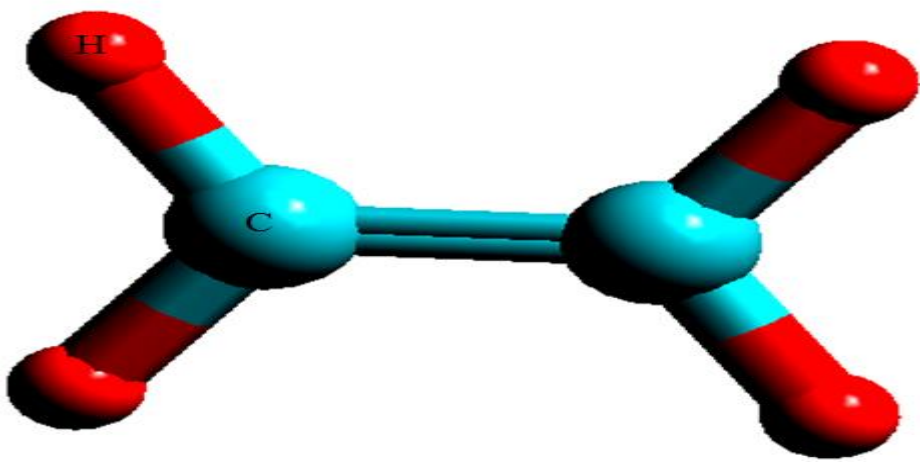




\section{Figure 6 : Geometry optimized of ethene predicted at DFT / B3LYP /6-31 G* level of theory.}

The fourth photodissociation pathway is a rearrangement reaction of primary radical to give a secondary radical which is more stable. The secondary radical has two pathways, the first pathway is R6 to give cyclopropane and bromine radical. The second path of secondary free radical is a conversion into a propene molecule and released bromine radical $\mathrm{R} 7$ reaction. The suggested fifth pathway of photolysis is a direct transformation of primary free radical into a cyclopropane which is the preferred and the most probable pathway while the last pathway is the isomerization of cyclopropane to propene.

The isomerization of cyclopropane to propene directly has an energy barrier equal to $64-66 \mathrm{kCal} \mathrm{mol}^{-1}$ which is calculated experimentally. The energy barrier computed by $\mathrm{MNDO} / \mathrm{d}$ method recorded lower value compared with the experimental value, to obtain an approximated value $A b$ initio or DFT computational methods must be used [24] . The suggested photolysis reactions summarized all the photolysis pathways as given in scheme 1.

The thermodynamic functions of the proposed reactions have been calculated by using a PM3 method as shown in Table 6 , where the rearrangement (R4) reaction of primary radical to secondary radical is exothermic and spontaneous reaction. The reactions of cyclopropane with bromine radical (R6, R8) also, exothermic and spontaneous reaction. 


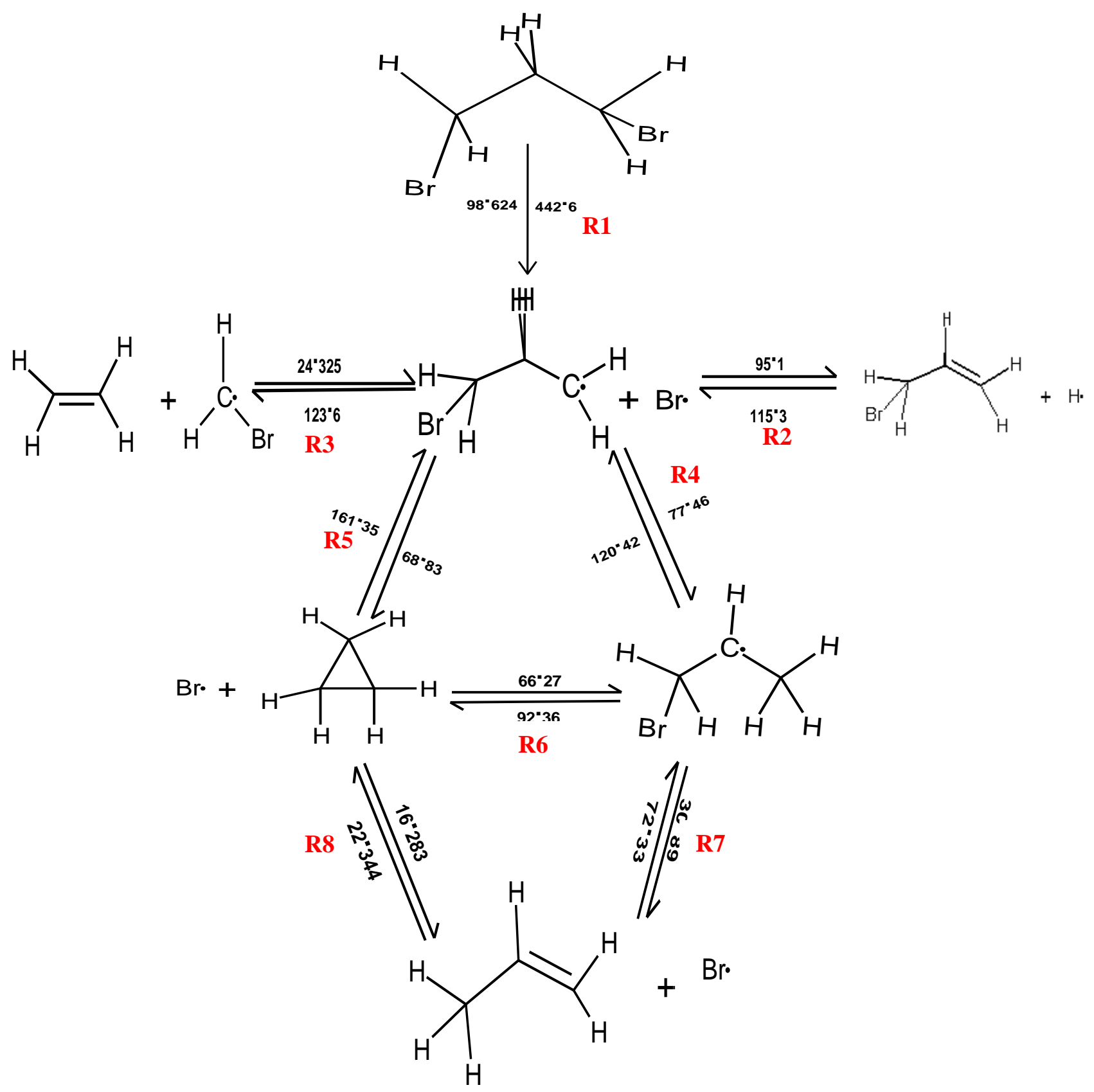

Scheme1. The proposed photolysis mechanism with energy barrier of 1,3-DBP calculated at semiempirical MNDO/d method. 


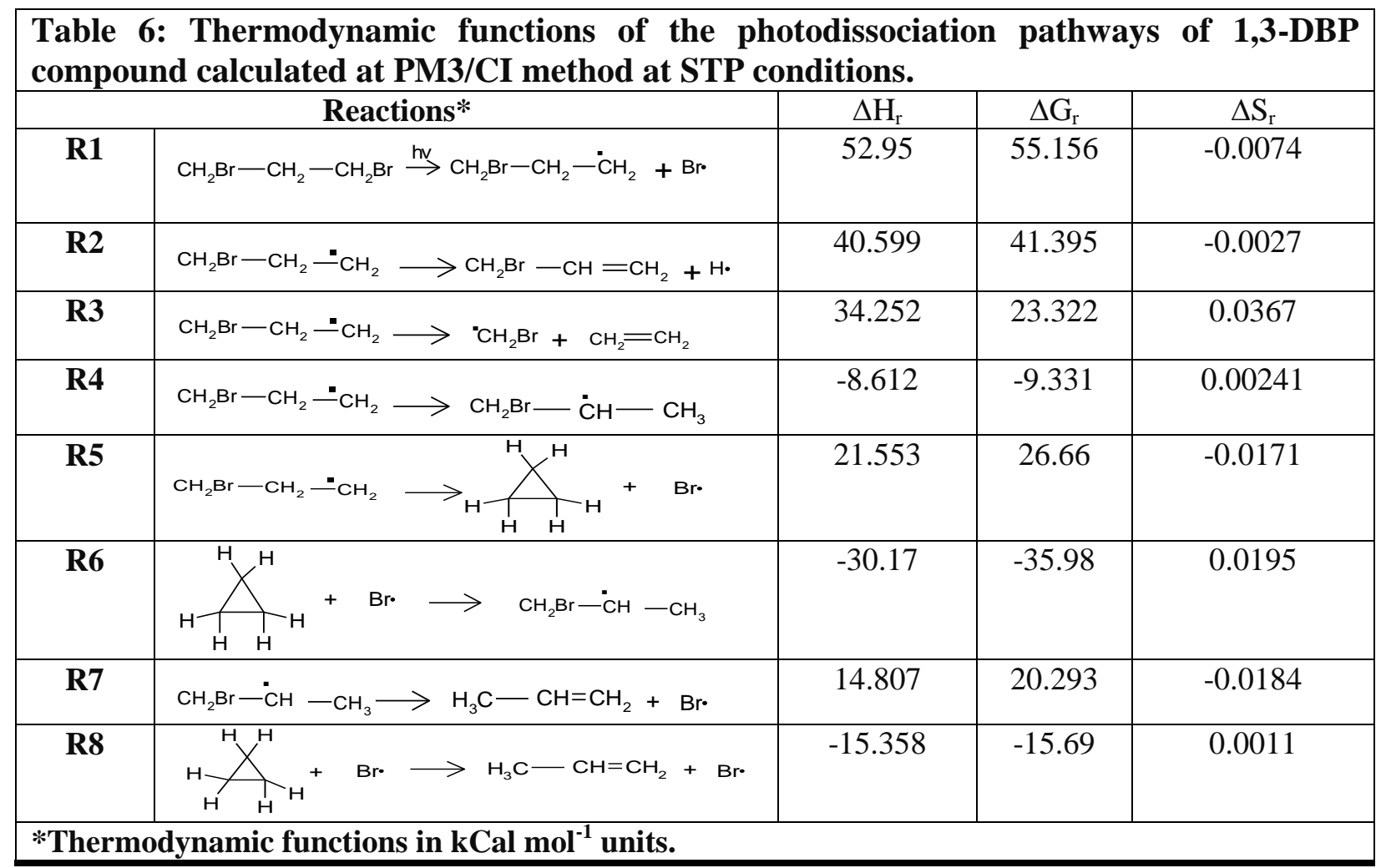

\section{Conclusion:}

1- 1,3-dibromopropane exists in three conformations $\mathrm{C}_{2}, \mathrm{C}_{1}$ and $\mathrm{C}_{2 \mathrm{~V}}$ which is found in this study that the $\mathrm{C}_{2}$ conformation is more stable than other conformations which is proved with a total energy being equal to -26652.031

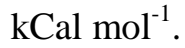

2- 1,3-dibromopropane breakdown at a wavelength equal to $442.571 \mathrm{~nm}$ to released bromine and 3bromopropane radicals with activation energy equal to 98.624 $\mathrm{kCal} \mathrm{mol}{ }^{-1}$.
3- There are eight pathways in photolysis mechanism of 1,3DBP, three of them through C-Br bond which give us different products, the other pathway is through C-H,C-C bonds, also rearrangement, transformation and isomerization pathway.

4- The most probable photolysis pathway is through R5 which give us cyclopropane and then isomerization to propene due to lowest value of activation energy.

\section{References:}


1- Chen, J-L. and Hu, W-P. 2011. Theoretical Prediction on the Thermal Stability of Cyclic Ozone and Strong Oxygen Tunneling. J. Am. Chem. Soc., 133(40), pp.16045-16053.

2- Daniel, J. S. Solomon, S. Portmann, R. W. and Garcia, R. R. 1999. Stratospheric ozone destruction: The importance of bromine relative to chlorine. Journal of Geophysical Research,104(D19),pp.23871-23880.

3- Kanakidou, M. Dentener, F. J. and Crutzen, P. J. 1995. A global threedimensional study of the fate of HCFCs and HFC-134a in the troposphere. Journal of Geophysical Research, 100(D9), pp.18781-18801.

4- Yamada, T. Fang, T. D. Taylor P. H. and Berry, R. J. 2000. Kinetics and Thermochemistry of the $\mathrm{OH}$ Radical Reaction with $\mathrm{CF}_{3} \mathrm{CCl}_{2} \mathrm{H}$ and $\mathrm{CF}_{3} \mathrm{CFClH}$. J. Phys. Chem. A, 104( 21), pp.5013-5022.

5- Drea, A. A. and A-Hussien, R. 2016.

Theoretical study of ozone depletion by Halon-1211. Research Journal of Pharmaceutical, Biological and Chemical Sciences, 7( 6), pp.1358-1367.

6- Dixon, D. A. de Jong, W. A. Peterson, K. A. and Francisco, J. S. 2002. Heats of Formation of $\mathrm{CBr}$, $\mathrm{CHBr}$, and $\mathrm{CBr}_{2}$ from $\mathrm{Ab}$ Initio Quantum Chemistry. J. Phys. Chem. A,106(18), pp.4725-4728.

7- M.-Avilés,M. Yang,S. and Francisco, J.S. 2008. Structure and vibrational spectra of bromine reservoir species from the atmospheric oxidations of bromoethane and bromopropane. Molecular Physics,106(2-4), pp.299314.

8- Kalume, A. George, L. El-Khoury, P. Z. Tarnovsky, A. N. and Reid, S. A. 2010. Spectroscopic And Computational Studies Of The Laser
Photolysis Of Matrix Isolated 1,2dibromoethanes: Formation And Fate Of The Bromoethyl Radicals . J. Phys. Chem. A, 114 (36), pp.9919-9926.

9- Zhang, D. 2011. Ultraviolet photodissociation of bromopropane: Energy partitioning and curve potential crossing analysis. Russian Journal of Physical Chemistry A, 85(7), pp.1274-1279.

10- A-Hussein, A. and Drea, A. A. 2012. Theoretical investigation study of Bromine radical reaction with ozone in stratospheric layer. Journal of Applicable Chemistry, 1(3), pp.453459.

11- Pugh, D. S. 2011. "Novel Methods for the Synthesis of Small Ring Systems", $\mathrm{PhD}$. Thesis, York University.

12- Kötting, C. Diau, E.W.-G. Sølling, T. I. and Zewail, A. H. 2002. Coherent Dynamics in Complex Elimination Reactions: Experimental and Theoretical Femtochemistry of 1,3Dibromopropane and Related Systems. J. Phys. Chem. A, 106( 33), pp.7530-7546.

13- Drea, A. A. and Izet, N. 2012. Mechanism and Kinetic of Free Radical Reactions for Propane Using theoretical Calculations J. Chem. Chem. Eng., 6, pp.563-573.

14- Drea, A. A. and A-Hussien, R. 2016. Simulation study of ozone depletion through photolysis mechanism of HCFC-124. Journal of Multifunctional Materials \& Photoscience,7(2), pp.99110.

15- M.-Avilés, M. R.-Reyes, C.M. and Francisco, J. S. 2008. HydroxylRadical-Initiated Oxidation Mechanism of Bromopropane. $J$. Phys. Chem. A, 112(34), PP.79307938.

16- Drea, A.A., 2016. Transition State Study Of Ozone Depletion By 1, 2- 
Dibromo 1,2-Dichloro Ethane

Theoretically. Int. J. Chem. Sci., 14 (1), pp.1-15.

17- Obies, M. H. Drea, A. A. and Hussein, F. H. 2012. Simulation Study Of Photocatalytic Decolorization Of Bismarck Brown-R Using Different Quantum Calculation Methods. Int. J. Chem. Sci., 10( 1), pp.63-79.

18- Adnan, H. Aowda, S. A. and Drea, A. A. 2014. Simulation Study of alkylation reaction of resorcinol. Journal of Applicable Chemistry, 3 (6), pp.2365-2371.

19- Postmyr, L. 1994. The molecular structures and conformational compositions of 1-bromo-3chloropropane and 1,3-diiodopropane, as determined by gas-phase electron diffraction and molecular mechanics calculations. Journal of Molecular Structure, 319, pp.211-221.

20- Rydland, T. and Stølevik, R. 1983. Molecular mechanics calculations of conformational structures, energies and barrier heights in chloro-and bromoalkanes. Journal of Molecular Structure, 105, pp.157-168.

21- Farup, P. E. Stølevik, R. 1974. Conformational Analysis VI. The Molecular Structure, Torsional Oscillations , and Conformational Equilibria of Gaseous 1,2,3Trichloropropane as Determined by Electron Diffraction and Compared with Semi-empirical (molecular mechanics) Calculations. Acta chemica Scandinavica, A28, pp.871884.

22- Drea, A .A. 2010. Photolysis of Raxil DS2 in aqueous solution by sun light through transition state computational study. National Journal of Chemistry., 37, pp. 86-100.

23- Feng, Y. Liu, L. Wang, J.-T. Zhao, S.-W. and Guo, Q.-X. 2004.
Homolytic C-H and N-H Bond Dissociation Energies of Strained Organic Compounds. J. Org.Chem., 69, pp. 3129-3138.

24- Bettinger, H. F. Rienstra-Kiracofe, J. C. Hoffman, B.C. Schaefer, H. F. Baldwinand, J. E. Schleyer, V. R. 1999. Structural isomerization of cyclopropane: a new mechanism through propylidene. Chem. Commun., pp.1515-1516. 